\title{
Registro Español de Trasplante Cardiaco. XXVII Informe Oficial de la Sección de Insuficiencia Cardiaca y Trasplante Cardiaco de la Sociedad Española de Cardiología (1984- 2015)
}

\author{
Francisco González-Vílchez ${ }^{\mathrm{a}, \mathrm{b}}$, Javier Segovia Cubero ${ }^{\mathrm{c}}$, Luis Almenar ${ }^{\mathrm{d}}$, María G. \\ Crespo-Leiro ${ }^{\mathrm{e}}$, José M. Arizón ${ }^{\mathrm{f}}$, Iago Sousa ${ }^{\mathrm{g}}$, Juan Delgado ${ }^{\mathrm{h}}$, Eulalia Roig ${ }^{\mathrm{i}}$, José \\ Manuel Sobrino ${ }^{\mathrm{j}}$, José González-Costello ${ }^{\mathrm{k}}$ \\ ${ }^{a}$ Registro Español de Trasplante Cardiaco, Sección de Insuficiencia Cardiaca y Trasplante Cardiaco, \\ Sociedad Española de Cardiología, Madrid, España \\ ${ }^{b}$ Servicio de Cardiología, Hospital Universitario Marqués de Valdecilla, Instituto de Investigación Marqués \\ de Valdecilla (IDIVAL), Santander, Cantabria, España \\ ${ }^{c}$ Servicio de Cardiología, Clínica Puerta de Hierro, Majadahonda, Madrid, España \\ ${ }^{d}$ Servicio de Cardiología, Hospital Universitario y Politécnico La Fe, Valencia, España \\ ${ }^{e}$ Instituto de Investigación Biomédica de A Coruña (INIBIC), Complexo Hospitalario Universitario de A \\ Coruña (CHUAC), SERGAS, Universidade da Coruña (UDC), A Coruña, España \\ ${ }^{f}$ Servicio de Cardiología, Hospital Universitario Reina Sofía, Córdoba, España \\ ${ }^{g}$ Servicio de Cardiología (Adultos), Hospital Universitario Gregorio Marañón, Madrid, España \\ ${ }^{h}$ Hospital Universitario 12 de Octubre, Madrid, España \\ ${ }^{i}$ Hospital Universitario de la Santa Creu i Sant Pau, Barcelona, España \\ ${ }^{j}$ Hospital Universitario Virgen del Rocío, Sevilla, España \\ ${ }^{k}$ Hospital Universitario de Bellvitge, L'Hospitalet de Llobregat, Barcelona, España
}

\section{Resumen}

Introducción y objetivos. Se presentan las características y los resultados del trasplante cardiaco en España desde que empezó su actividad en mayo de 1984.

Métodos. Se realiza un análisis descriptivo de las características de los receptores, los donantes, los procedimientos quirúrgicos y los resultados de los trasplantes cardiacos realizados en España hasta el 31 de diciembre de 2015.

Resultados. Durante 2015 se han realizado 299 procedimientos, con lo que la serie histórica consta de 7.588 trasplantes. Las características generales del procedimiento son similares a las observadas en los últimos años y destacan el alto porcentaje de procedimientos realizados en código urgente y, sobre todo, la extensión del uso de dispositivos de asistencia circulatoria, particularmente la asistencia ventricular de flujo continuo (el $16 \%$ del total de trasplantes). La supervivencia ha aumentado significativamente en la última década con respecto a periodos anteriores.

Conclusiones. La actividad de trasplante cardiaco en España permanece estable en los últimos años, con alrededor de 250-300 procedimientos al año. A pesar de la mayor complejidad del contexto clínico, se observa una mejora de la supervivencia en los últimos años.

\section{Palabras clave}

Trasplante cardiaco; Registro; Supervivencia. 


\section{INTRODUCCIÓN}

Desde 1991, el Registro Español de Trasplante Cardiaco (RETC) viene publicando la descripción de las características clínicas y quirúrgicas y los resultados generales de los procedimientos de trasplante cardiaco que se realizan en España ${ }^{1}{ }^{26}$. El presente artículo describe los datos referentes a la población trasplantada hasta el 31 de diciembre de 2015. Como ya es conocido, la mayor fortaleza del RETC reside en la inclusión y actualización exhaustiva de todos los procedimientos de trasplante cardiaco realizados en todos los hospitales de nuestro país desde mayo de 1984, independientemente de sus características y resultados. Además, la recogida de datos se realiza prospectivamente según una base de datos común consensuada y actualizada por todos los grupos.

\section{MÉTODOS}

\section{Pacientes y centros}

De los 19 centros que han aportado los datos al RETC, actualmente permanecen activos 18 (tabla 1). Dos centros se dedican únicamente al trasplante pediátrico y otros 3 mantienen actividad tanto en trasplante pediátrico como del adulto. El número de procedimientos realizados anualmente se resume en la figura 1. El total de la serie consta de 7.588 procedimientos. En 12 casos se ha producido una pérdida de datos, incluida información sobre el seguimiento. Estos no se incluyen en los análisis, con lo que el tamaño muestral finalmente queda formado por 7.576 casos. De los 299 procedimientos realizados en 2015, 22 casos $(7,4 \%)$ se realizaron en pacientes pediátricos (edad < 16 años). Los tipos de procedimientos realizados en 2015 y en la serie total se resumen en la tabla 2.

Tabla 1. Centros participantes (por orden de realización del primer trasplante) en el Registro Español de Trasplante Cardiaco (1984-2015)

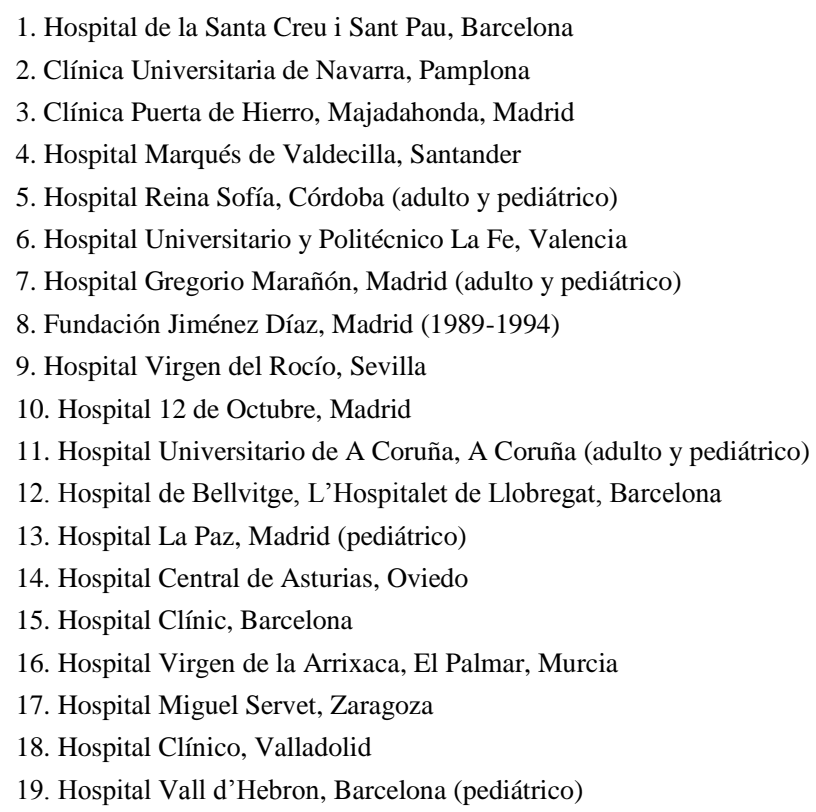




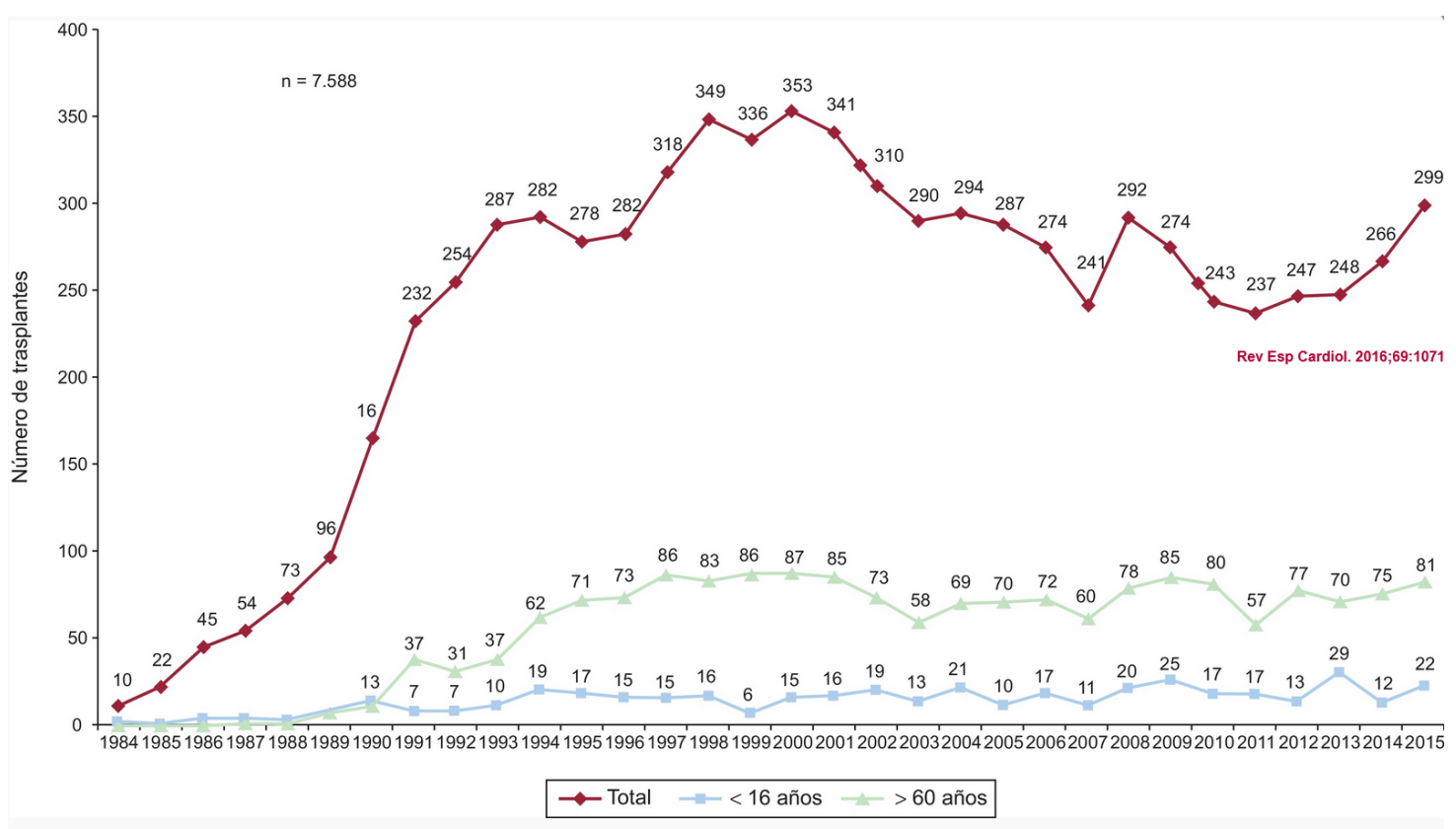

Figura 1. Número anual de trasplantes (1984-2015) total y por grupos de edad.

Tabla 2. Registro Español de Trasplante Cardiaco (1984-2015). Tipo de procedimiento

\begin{tabular}{lll}
\hline & & \\
Procedimiento & 2015 & $1984-2015$ \\
Trasplante cardiaco de novo & 292 & 7.243 \\
Retrasplante & 4 & 183 \\
Retrasplante combinado & 0 & $6^{\mathrm{a}}$ \\
Trasplantes combinados & 3 & 150 \\
Corazón-pulmón & 2 & 74 \\
Corazón-riñón & 1 & $67^{\mathrm{b}}$ \\
Corazón-hígado & - & 9 \\
Total & 299 & 7.576 \\
& & \\
\hline & & \\
\multicolumn{2}{l}{${ }^{\mathrm{b}}$ Todos los casos trasplante renal. } \\
\end{tabular}

\section{Procedimientos}

La base de datos consta de 175 variables clínicas, preestablecidas de manera consensuada por todos los grupos, que recogen datos del receptor, el donante, la técnica quirúrgica, la inmunosupresión y el seguimiento. Desde 2013, los datos se introducen y actualizan en formato electrónico en tiempo real mediante una aplicación disponible en internet y específicamente diseñada para tal propósito. El soporte de la base de datos es un archivo de Microsoft Excel. Este procedimiento sustituye al anterior, en el que cada centro enviaba los datos al director del registro en formato Microsoft Access mediante correo electrónico. Una CRO (contract research organization) externa, actualmente ODDS S.L., realiza el mantenimiento de la base de datos, el control de calidad y el análisis estadístico. 
La aprobación por el comité ético, la auditoría y el registro en el Ministerio de Sanidad se ha realizado según lo dispuesto en la Ley Orgánica de Protección de Datos 15/1999.

\section{Estadística}

Las variables cuantitativas continuas se presentan como media \pm desviación estándar y las categóricas, como porcentajes. Los resultados se categorizan según el año del trasplante, lo que divide la muestra total en 4 grupos (1984-1993, 1994-2003, 2004-2013 y 2014-2015). En algunas variables, como la edad del donante, los trasplantes urgentes y el tiempo de isquemia, también se analizaron los datos anuales de toda la serie. Las diferencias entre grupos se analizan mediante un test no paramétrico para la tendencia temporal ( $\tau$ de Kendall) en el caso de variables categóricas y test de análisis de la varianza con ajuste polinómico para las variables cuantitativas. Las curvas de supervivencia se han calculado mediante el test de Kaplan-Meier y la comparación entre ellas, mediante log rank test. Se ha considerado diferencia significativa las comparaciones con valor de $\mathrm{p}<0,05$.

\section{RESULTADOS}

\section{Características de los receptores}

En 2015, los receptores tuvieron una media de edad de 49,5 $\pm 16,5$ (intervalo, 0,14-73) años, el $76 \%$ eran varones, con diagnósticos basales mayoritarios de miocardiopatía isquémica $(21,4 \%)$, dilatada no isquémica $(30,4 \%)$, miocardiopatía de origen valvular $(4,0 \%)$ y otras etiologías $(44,2 \%)$. Las características de los pacientes trasplantados por periodo de trasplante se resumen en la tabla 3. Se observan tendencias significativas a mayor edad de los receptores, sexo femenino, etiologías no usuales de la cardiopatía de base y un aumento de las condiciones pretrasplante de reconocido efecto pronóstico, como la diabetes mellitus insulinodependiente y la infección, cirugía cardiaca y ventilación mecánica previas al trasplante. Aunque no estadísticamente significativa, la proporción de retrasplantes ha caído por debajo del 2\% en 2014-2015, y es del 2,4\% de la serie total. Por el contrario, se ha dado una disminución significativa de las resistencias vasculares pulmonares previas al trasplante y casi significativa para la disfunción renal grave previa al trasplante a lo largo de la serie temporal. 
Tabla 3. Características del receptor en el Registro Español de Trasplante Cardiaco (1984-2015)

\begin{tabular}{|c|c|c|c|c|c|c|}
\hline & $\begin{array}{l}1984-1993 \\
(\mathrm{n}=1.230)\end{array}$ & $\begin{array}{l}1994-2003 \\
(n=3.148)\end{array}$ & $\begin{array}{l}2004-2013 \\
(n=2.633)\end{array}$ & $\begin{array}{l}2014-2015 \\
(\mathrm{n}=565)\end{array}$ & $\begin{array}{l}\mathrm{p} \\
\text { (tendencia) }\end{array}$ & $\begin{array}{l}2015 \\
(n=299)\end{array}$ \\
\hline Edad (años) & $46,7 \pm 13,4$ & $50,4 \pm 14,6$ & $49,5 \pm 16,5$ & $49,7 \pm 16,1$ & $<0,001$ & $49,5 \pm 16,5$ \\
\hline$<16$ años & 3,9 & 4,8 & 6,8 & 6,0 & $<0,001$ & 7,4 \\
\hline$>60$ años & 10,0 & 24,3 & 27,3 & 27,6 & $<0,001$ & 27,1 \\
\hline Varones & 85,8 & 81,1 & 76,1 & 75,8 & $<0,001$ & 76,3 \\
\hline$I M C$ & $24,2 \pm 4,0$ & $25 \pm 4,5$ & $24,9 \pm 4,7$ & $24,7 \pm 4,4$ & $<0,001$ & $24,6 \pm 4,4$ \\
\hline Etiología de base & & & & & $<0,001$ & \\
\hline Dilatada no isquémica & 40,8 & 37,8 & 37,5 & 37,9 & & 36,8 \\
\hline Isquémica & 40,2 & 43,7 & 36,5 & 38,1 & & 39,5 \\
\hline Valvular & 10,4 & 7,6 & 7,8 & 4,1 & & 3,7 \\
\hline Otras & 8,6 & 10,8 & 18,1 & 20,0 & & 20,1 \\
\hline$R V P(U W)$ & $2,6 \pm 1,8$ & $2,3 \pm 1,8$ & $2,4 \pm 2,2$ & $2,2 \pm 1,3$ & $<0,001$ & $2,2 \pm 1,4$ \\
\hline Creatinina $>2 \mathrm{mg} / \mathrm{dl}$ & 7,0 & 6,1 & 8,3 & 5,8 & 0,058 & 5,7 \\
\hline Bilirrubina $>2 \mathrm{mg} / \mathrm{dl}$ & 19,7 & 17,8 & 18,2 & 16,4 & 0,436 & 16,0 \\
\hline $\begin{array}{l}\text { Diabetes } \\
\text { insulinodependiente }\end{array}$ & 8,5 & 12,9 & 17,0 & 23,9 & $<0,001$ & 26,2 \\
\hline EPOC moderada-grave & 9,3 & 11,2 & 9,4 & 12,2 & 0,044 & 10,9 \\
\hline Infección previa & 4,0 & 9,4 & 13,7 & 12,7 & $<0,001$ & 11,5 \\
\hline Cirugía cardiaca previa & 25,3 & 26,5 & 28,9 & 33,8 & 0,001 & 37,1 \\
\hline Retrasplante cardiaco & 2,8 & 2,1 & 2,6 & 1,8 & 0,84 & 1,3 \\
\hline $\begin{array}{l}\text { Ventilación mecánica } \\
\text { pretrasplante }\end{array}$ & 8,3 & 10,3 & 16,2 & 13,8 & $<0,001$ & 15,7 \\
\hline Trasplante urgente & 18,1 & 23,6 & 34,6 & 44,4 & $<0,001$ & 47,2 \\
\hline
\end{tabular}

IMC: índice de masa corporal; EPOC: enfermedad pulmonar obstructiva crónica; RVP: resistencias vasculares pulmonares. Las cifras en el apartado Etiología de base difieren de informes anteriores debido a la actualización de la base de datos y recodificación de las distintas categorías. Los valores expresan porcentajes o media \pm desviación estándar.

En 2015 se observa cierto repunte del trasplante urgente respecto a 2014, pues alcanza prácticamente la mitad de los procedimientos. Esto mantiene la tendencia a la realización de trasplante urgente por encima del 40\% desde 2013 (figura 2). Se confirma en 2015 la extensión del uso de dispositivos de asistencia ventricular pretrasplante detectada desde 2009 ( $p<0,001$ ) (figura $3)$. Durante el último año, sin embargo, se evidencia un incremento porcentual del uso de dispositivos de asistencia de flujo continuo $(33,9 \%)$ y un descenso prácticamente a la mitad respecto a 2014 del balón de contrapulsación (figura 4). 


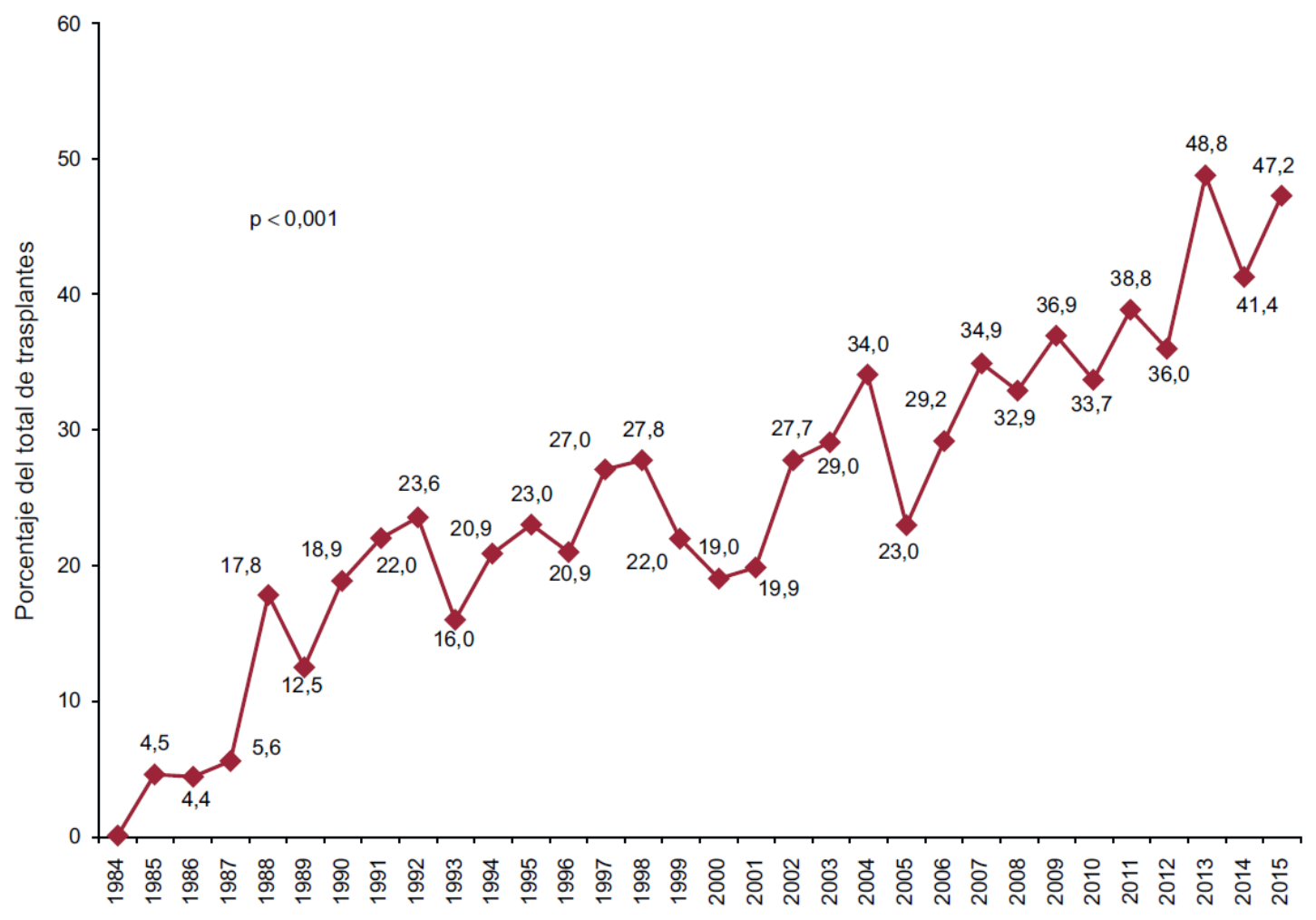

Figura 2. Porcentaje anual de trasplantes urgentes sobre la población total (1984-2015).

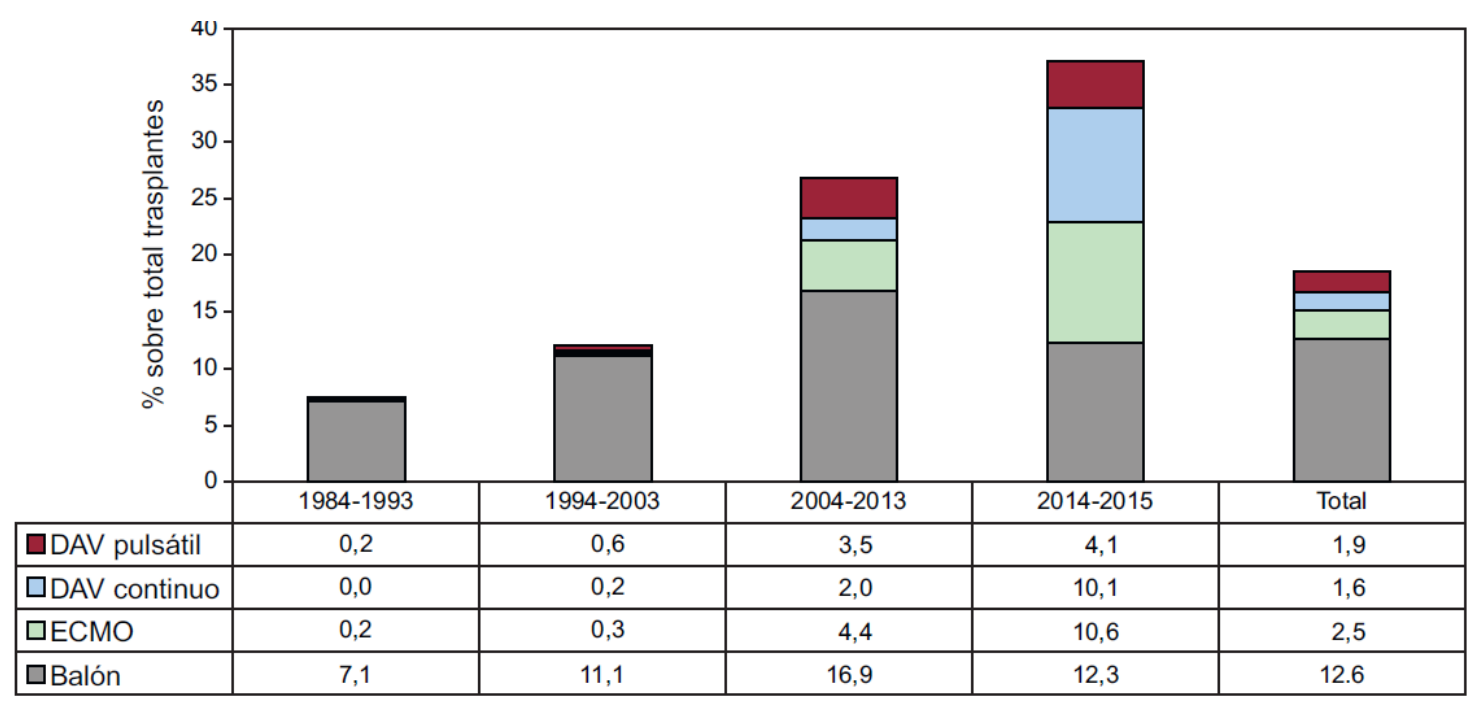

Figura 3. Distribución del tipo de asistencia circulatoria previa al trasplante por periodos (1984-2015). DAV: dispositivo de asistencia ventricular; ECMO: oxigenador extracorpóreo de membrana. 


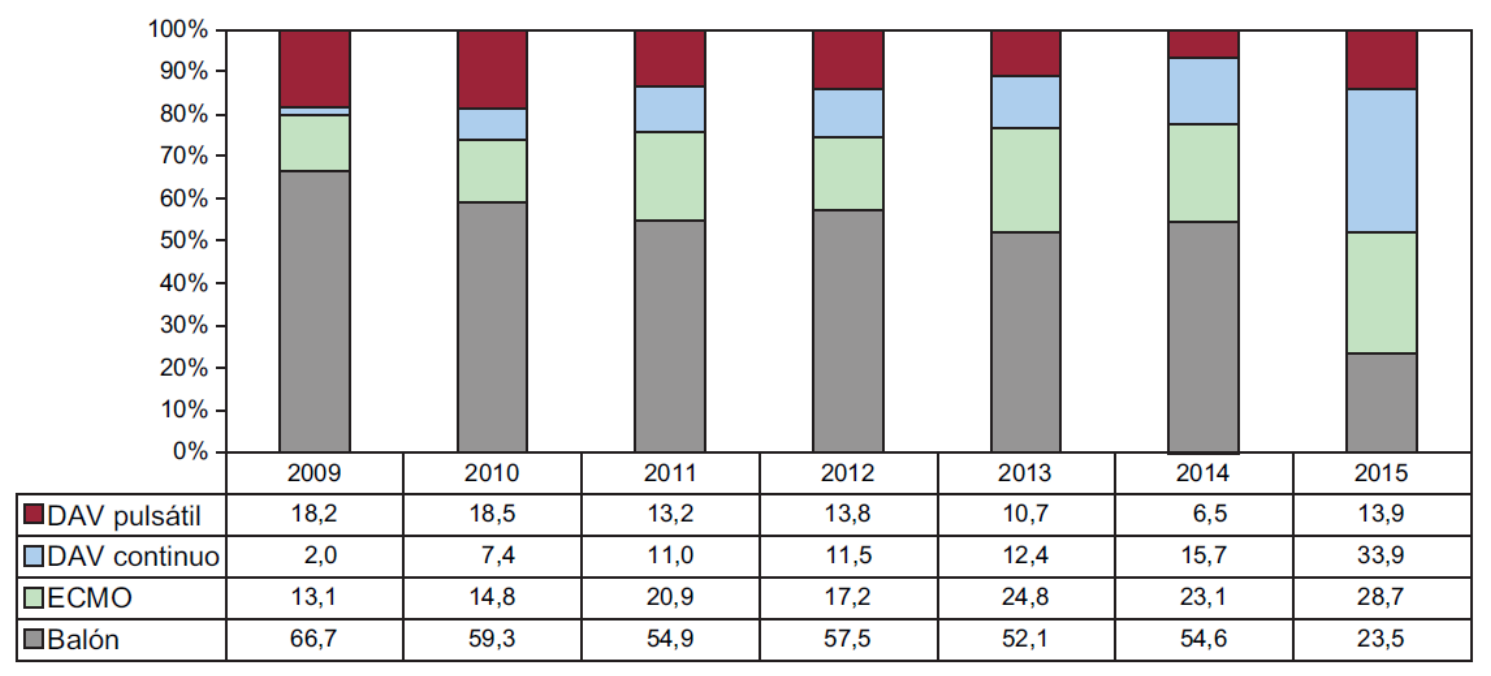

Figura 4. Distribución del tipo de asistencia circulatoria previa al trasplante por años (2009-2015). DAV: dispositivo de asistencia ventricular; ECMO: oxigenador extracorpóreo de membrana.

\section{Características de los donantes y tiempo de isquemia}

Las características de los donantes según el intervalo de tiempo y en 2015 se resumen en la tabla 4. La edad del donante ha ido incrementándose significativamente a lo largo de la serie, con un porcentaje de donantes considerados no óptimos (edad > 45 años) del 55\% en 2015 (figura 5). Han seguido incrementándose los donantes de sexo femenino y el porcentaje de trasplantes realizados a receptor varón de donante mujer $(26,4 \%)$, con parada cardiaca previa a la donación (el $21,8 \%$ en 2015). Asimismo, se confirma el aumento de los donantes fallecidos por accidente cerebrovascular en detrimento de los fallecidos por traumatismo (figura 6). 
Tabla 4. Características de los donantes y tiempos de isquemia en el Registro Español de Trasplante Cardiaco (1984-2015)

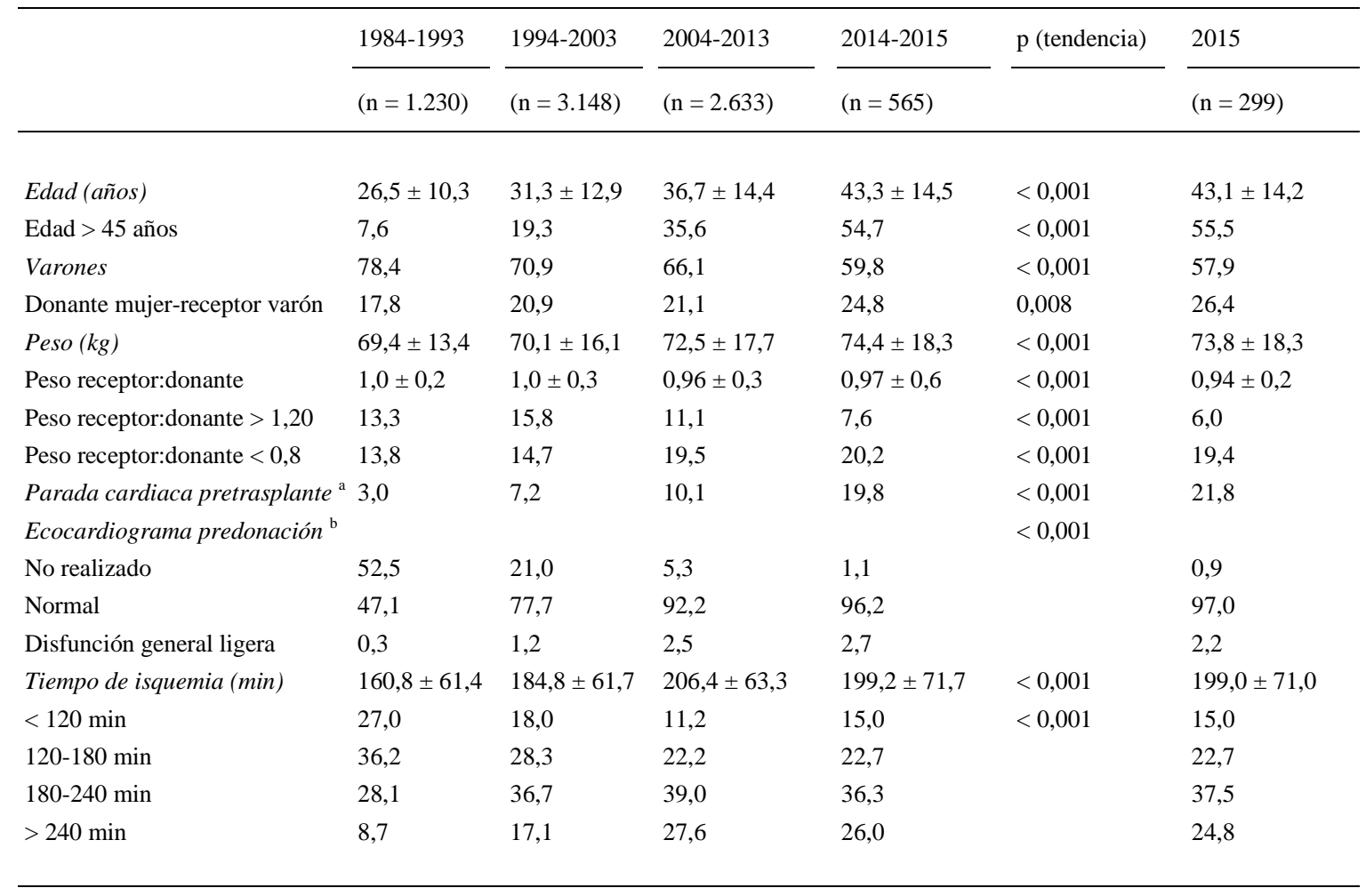

Los valores expresan porcentajes o media \pm desviación estándar.

a Sobre 4.039 trasplantes.

${ }^{\mathrm{b}}$ Sobre 6.361 trasplantes.

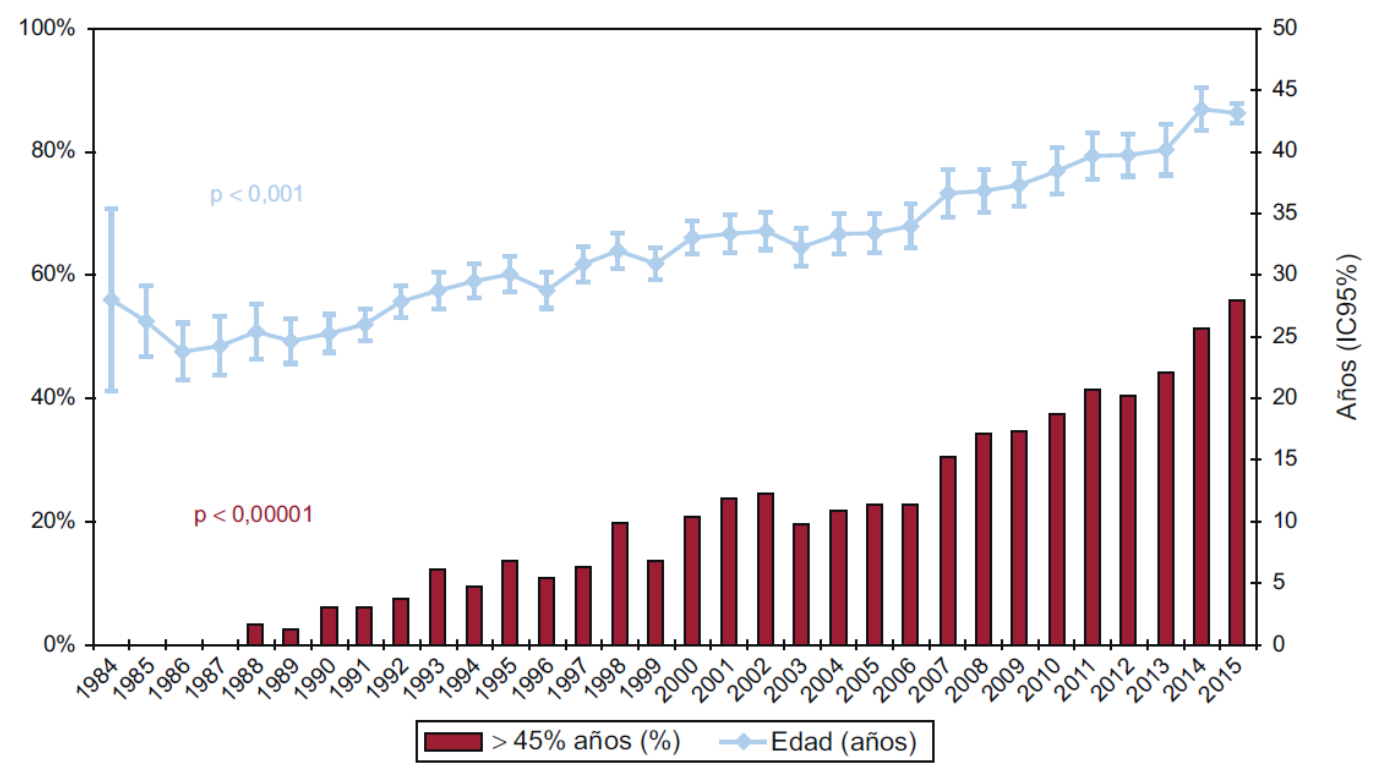

Figura 5. Evolución anual de la edad del donante y el porcentaje de donantes con edad > 45 años (1984-2015). IC95\%: intervalo de confianza del $95 \%$. 


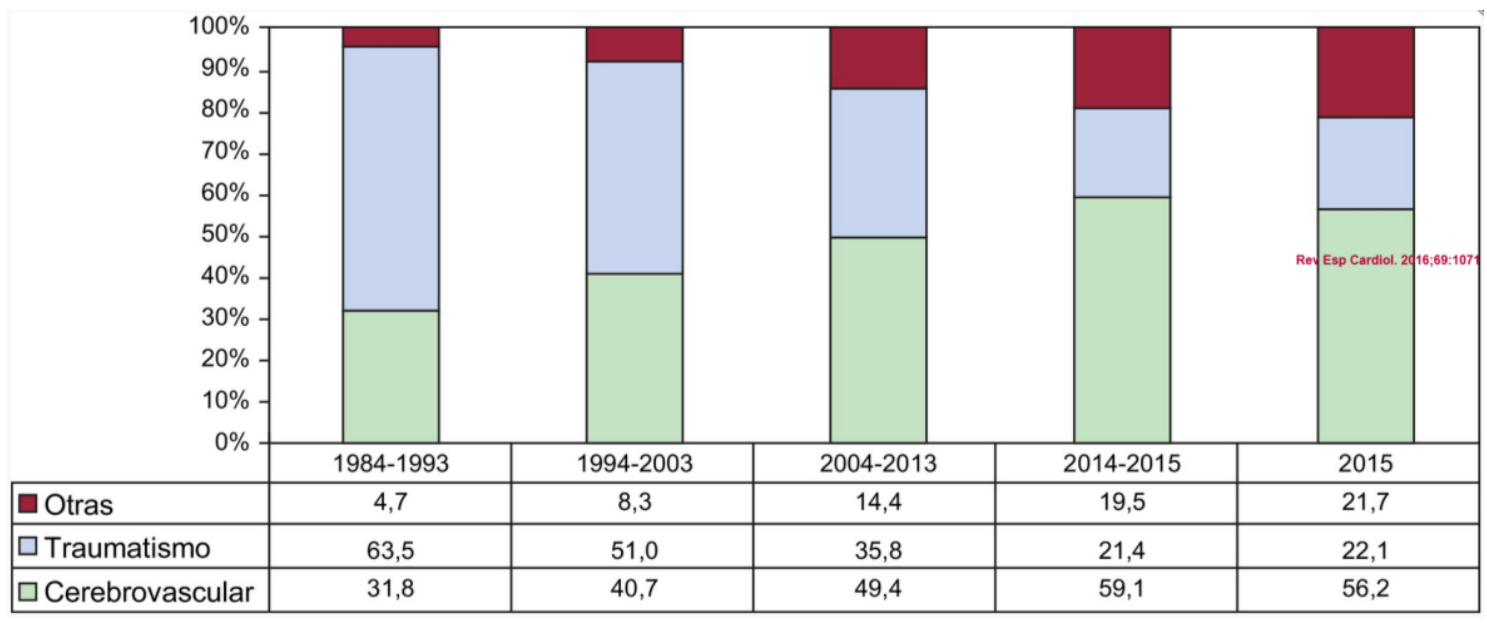

Figura 6. Evolución de las causas de muerte de los donantes cardiacos, por periodos.

El tiempo de isquemia se ha incrementado a lo largo de la serie temporal. En 2015, tal como ocurrió en la década previa, aproximadamente un cuarto de los pacientes recibieron el trasplante con un tiempo de isquemia $>240$ min (tabla 4 y figura 7).

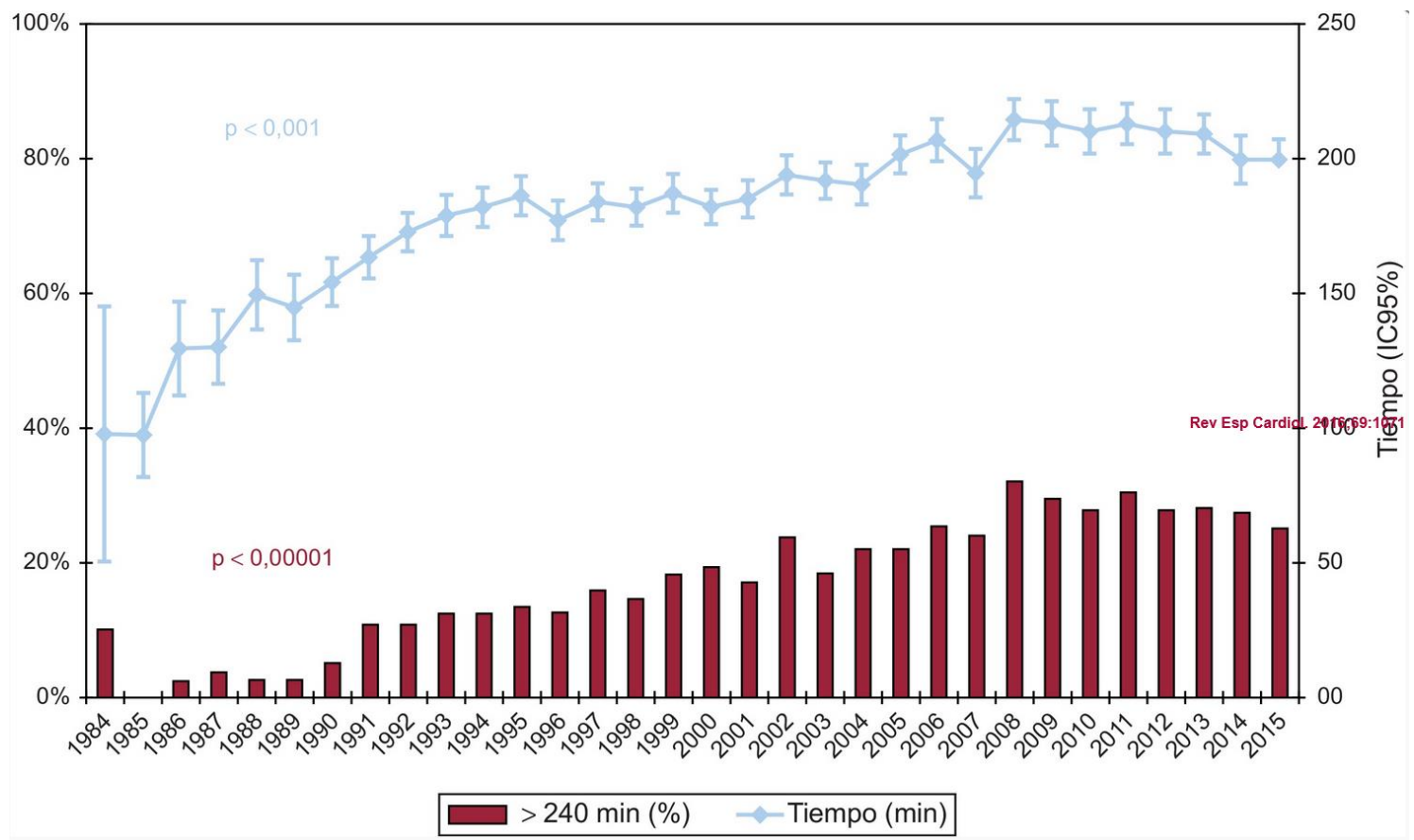

Figura 7. Evolución anual de tiempo de isquemia y porcentaje de tiempo de isquemia > $240 \mathrm{~min}$ (1984-2015). IC95\%: intervalo de confianza del $95 \%$. 


\section{Inmunosupresión}

En 2015, el 83,4\% de los receptores recibieron algún tratamiento inmunosupresor de inducción, en su inmensa mayoría con basiliximab (79,1\%) (figura 8), lo que confirma la tendencia observada desde 2009.

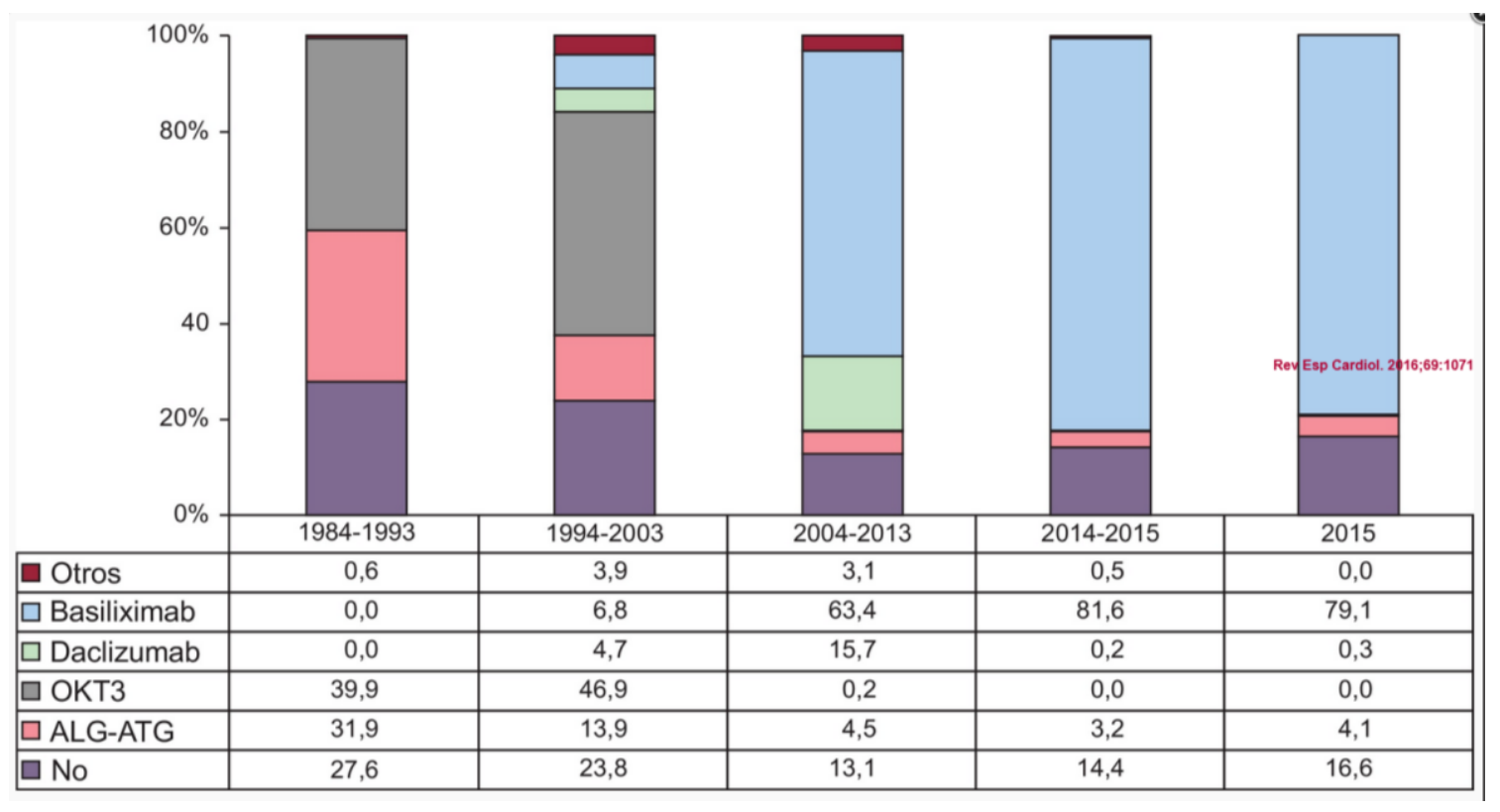

Figura 8. Fármacos utilizados en la inmunosupresión de inducción. ALG: globulina antilinfocitaria; ATG: globulina antitimocitaria.

En la figura 9 se resumen los fármacos usados en la inmunosupresión inicial y al final del seguimiento para la serie total. En un seguimiento promedio de 7,2 años, el 63,1\% de los pacientes continuaban en tratamiento con corticoides. El $30 \%$ de los pacientes estaban en tratamiento con inhibidores de la mTor (everolimus o sirolimus) en el último seguimiento. 


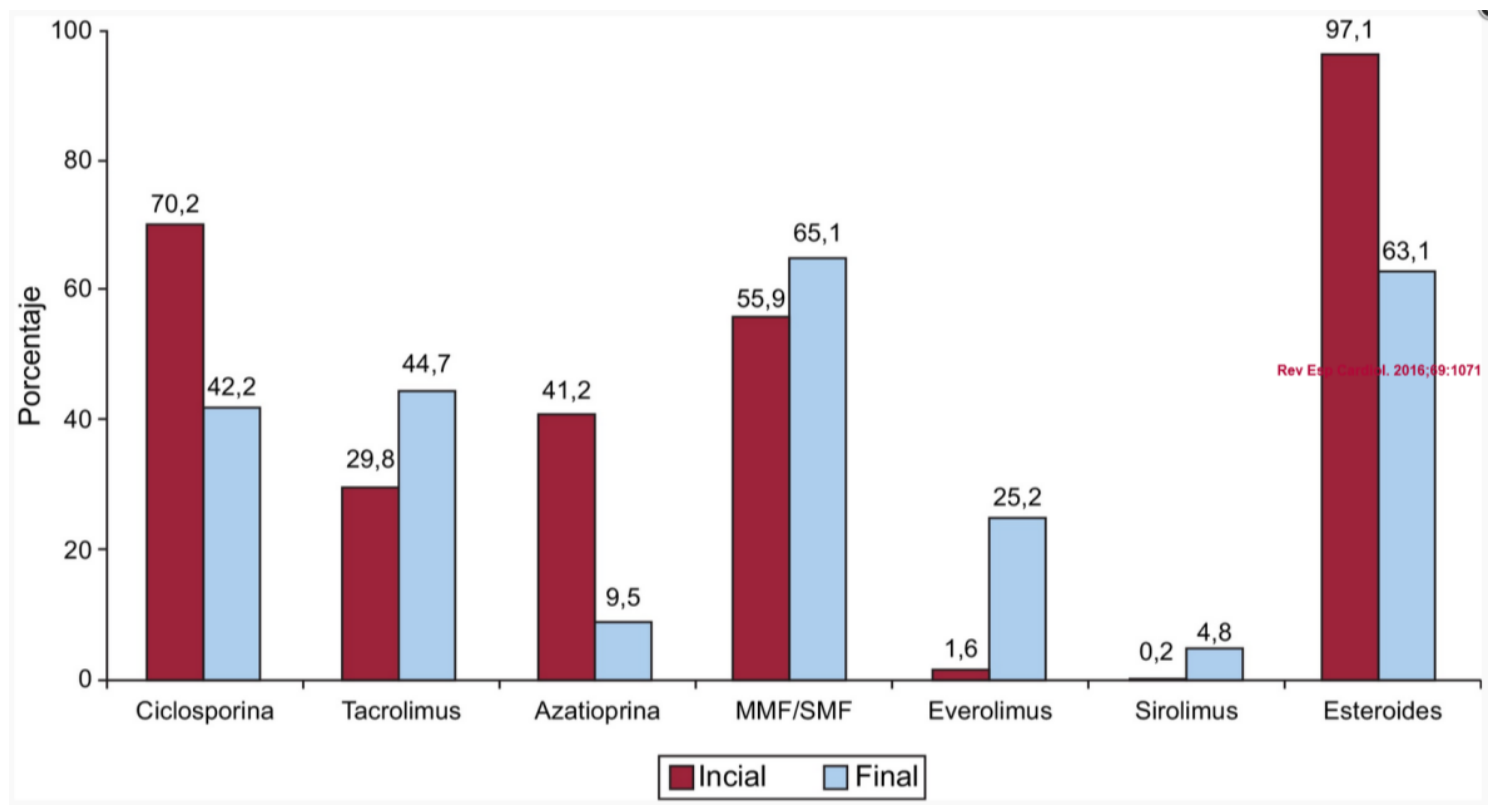

Figura 9. Inmunosupresión inicial y de mantenimiento en toda la serie (1984-2015). Variaciones evolutivas según el tipo de fármaco: al inicio del trasplante y al final del seguimiento. MMF: micofenolato mofetilo; SMF: micofenolato sódico.

La inmunosupresión de inicio en 2015 se realizó mayoritariamente con tacrolimus (89,3\%) como inhibidor de la calcineurina, micofenolato mofetilo o ácido micofenólico $(98,3 \%)$ como antiproliferativo y esteroides $(98,3 \%)$. La evolución anual del uso de los distintos inhibidores de la calcineurina y antimitóticos se muestra en la figura 10 y la figura 11 , respectivamente. La evolución anual del uso de inhibidores de mTor (sirolimus, everolimus) en la inmunosupresión de inicio se muestra en la figura 12. 


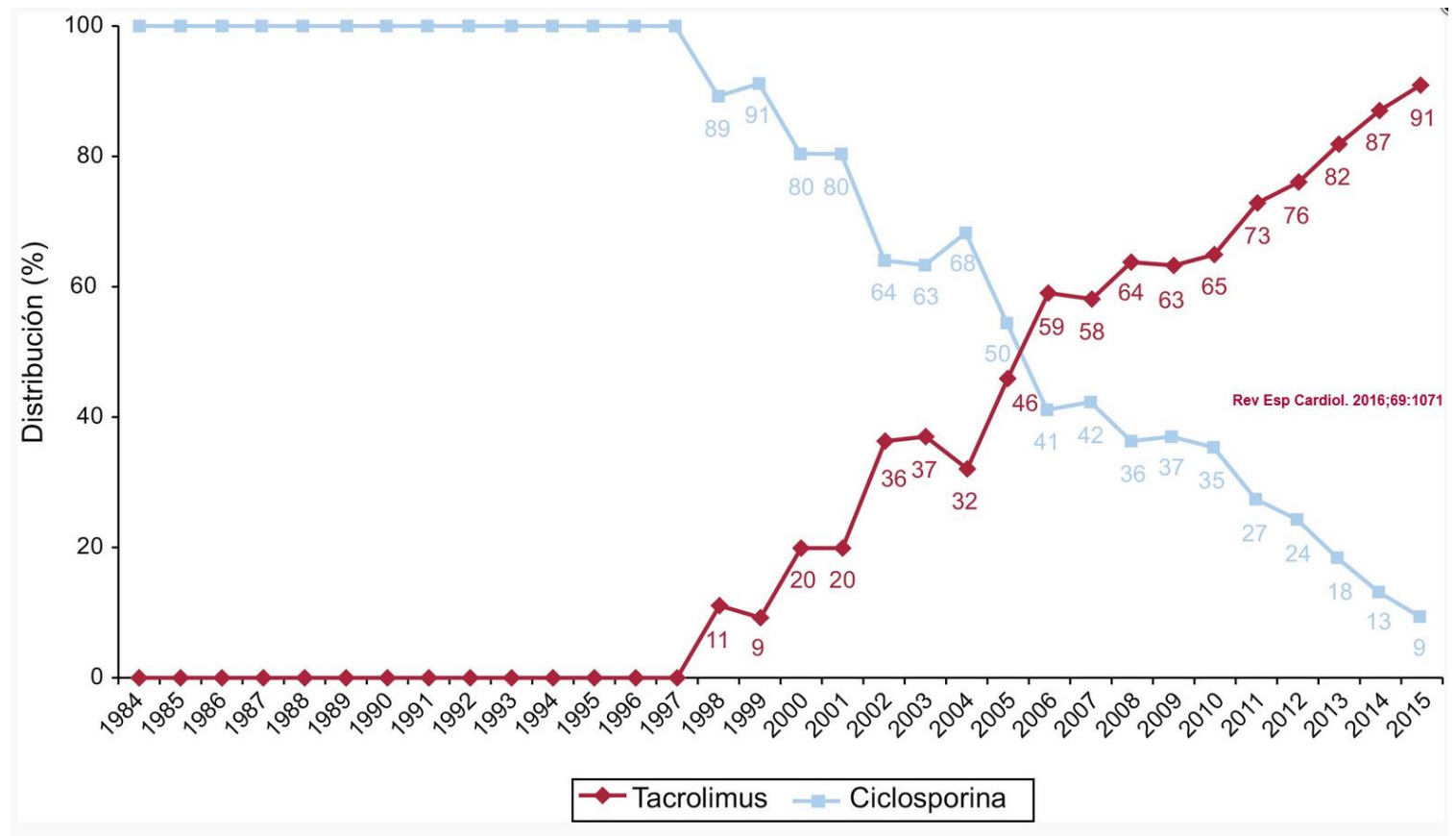

Figura 10. Evolución anual del uso de inhibidores de calcineurina (ciclosporina y tacrolimus) en la inmunosupresión de inicio en la muestra total (1984-2015).

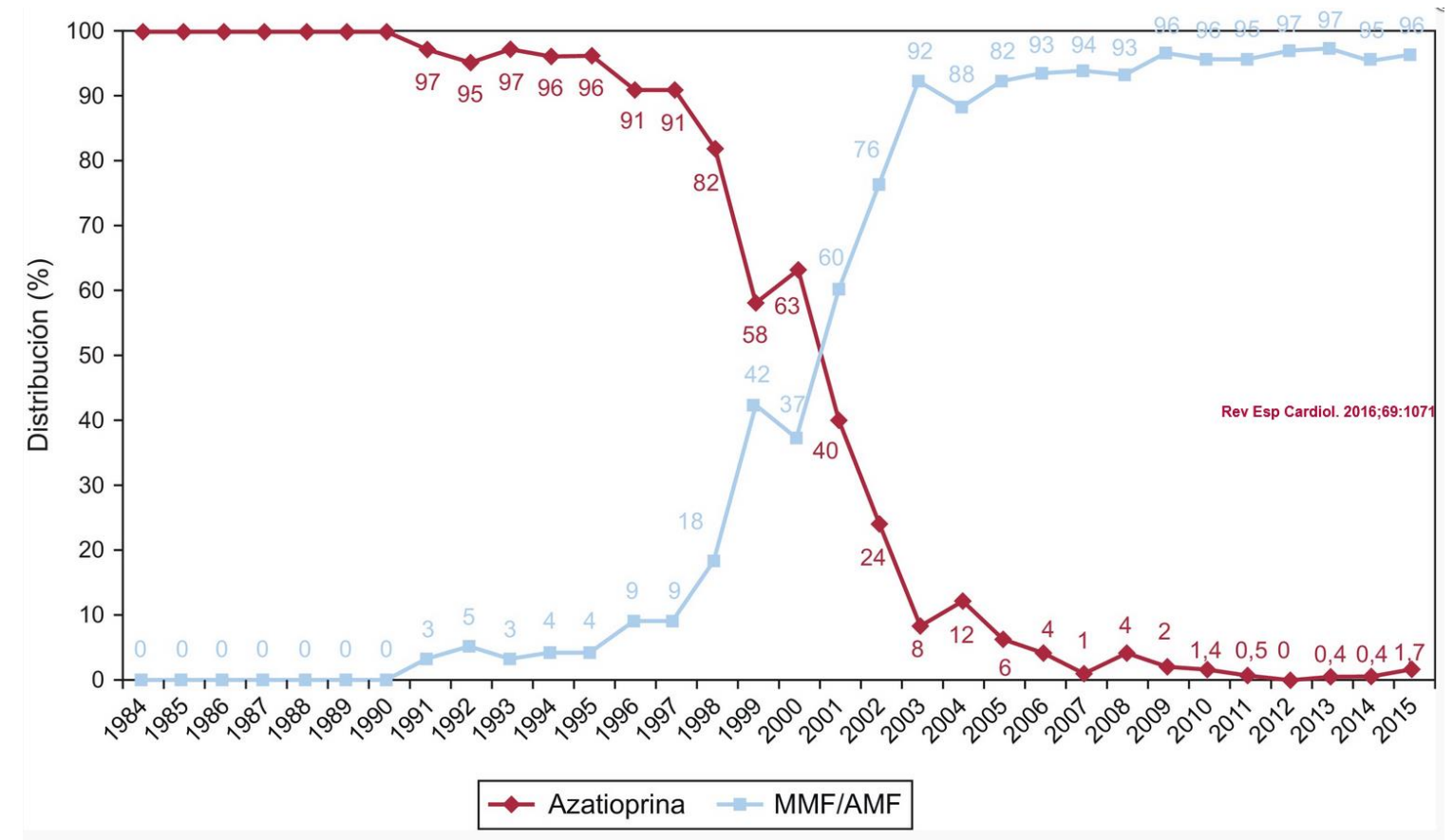

Figura 11. Evolución anual del uso de antimitóticos (azatioprina y micofenolato mofetilo/ácido micofenólico) en la inmunosupresión de inicio en la muestra total (1984-2015). AMF: ácido micofenólico; MMF: micofenolato mofetilo 


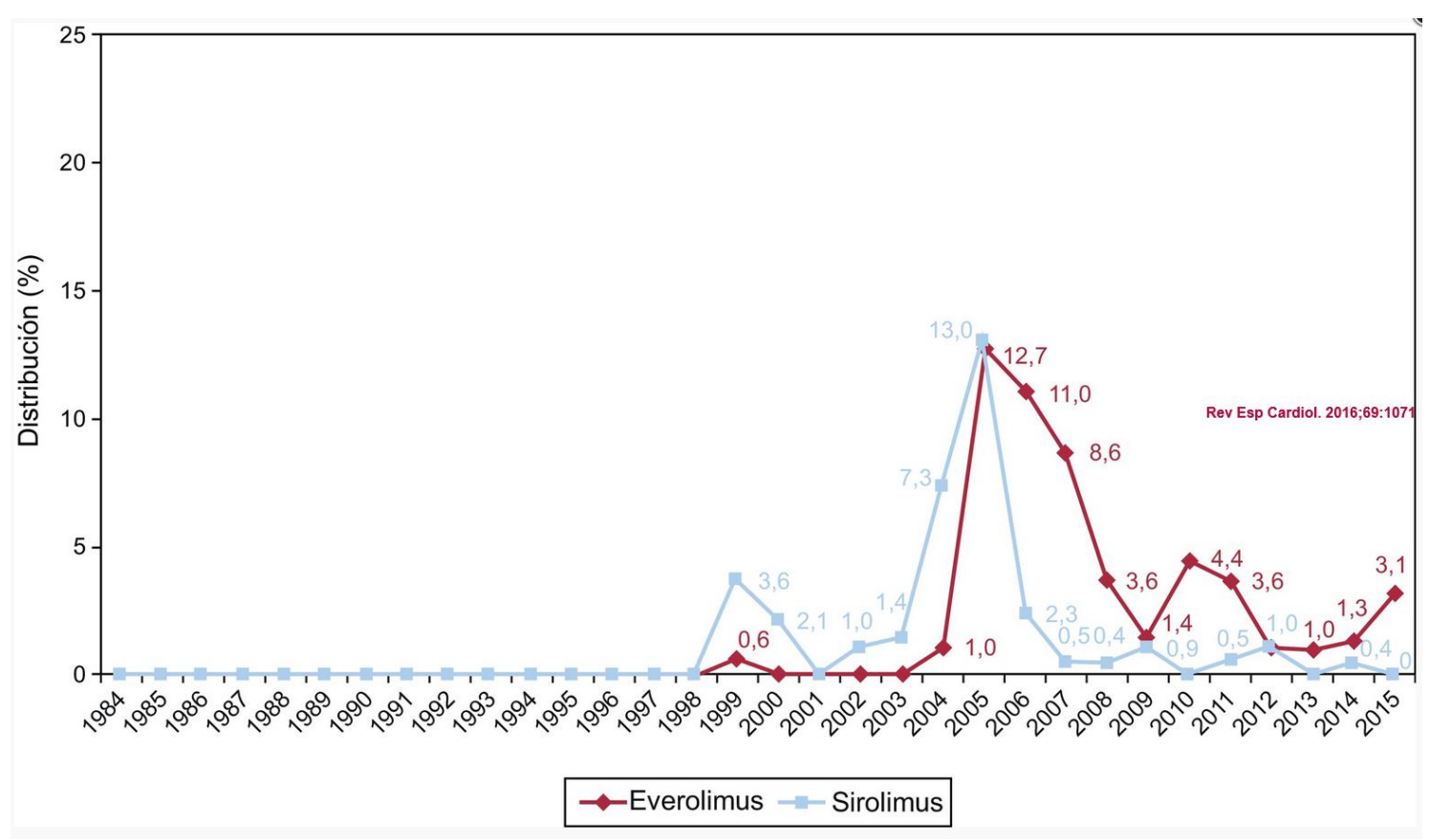

Figura 12. Evolución anual del uso de inhibidores de mTor (sirolimus y everolimus) en la inmunosupresión de inicio en la muestra total (1984-2015). Los puntos no rotulados se corresponden con valor 0.

\section{Supervivencia}

Con fecha de última actualización 31 de diciembre de 2015, la supervivencia actuarial en el conjunto de la serie a 1, 5, 10, 15 y 20 años se resume en la figura 13. Esto supone una mortalidad promedio de aproximadamente un 2-3\% anual después del primer año tras el trasplante, con una mediana de supervivencia de 11,1 años. La supervivencia condicionada a 1 año se muestra en la figura 14. La mediana de supervivencia condicionada a superar el primer año de trasplante es de 15,1 años. Hubo diferencias significativas según la edad del receptor, la edad del donante, el tipo de procedimiento (trasplante aislado, combinado y retrasplante), el código de urgencia y el tipo de asistencia circulatoria en el momento del trasplante (sin asistencia, balón de contrapulsación, oxigenador extracorpóreo de membrana [ECMO], dispositivo de asistencia ventricular). Lo más destacable es la supervivencia similar respecto al trasplante electivo de los trasplantes realizados con balón de contrapulsación o dispositivos de asistencia ventricular. Los trasplantes realizados con ECMO previa muestran una supervivencia significativamente menor que los realizados sin ningún dispositivo. 


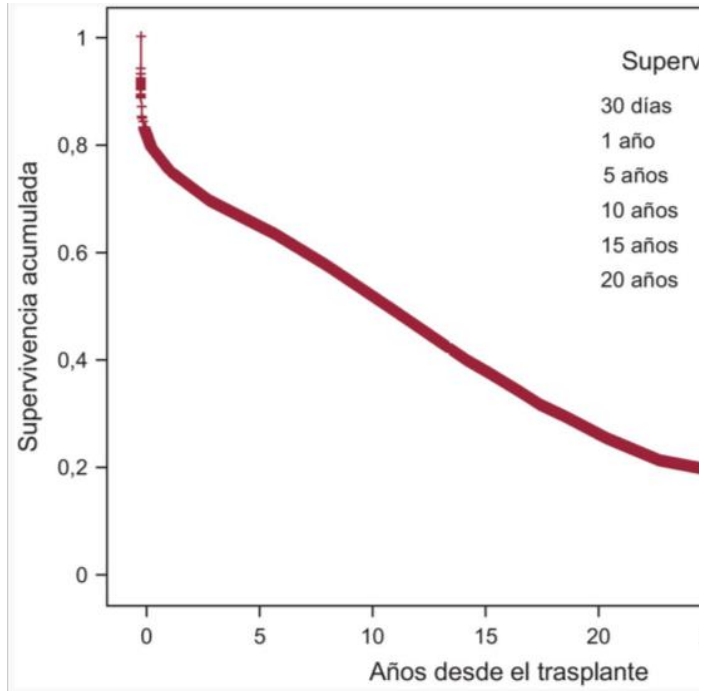

Figura 13. Curva de supervivencia total de toda la serie (1984-2015).

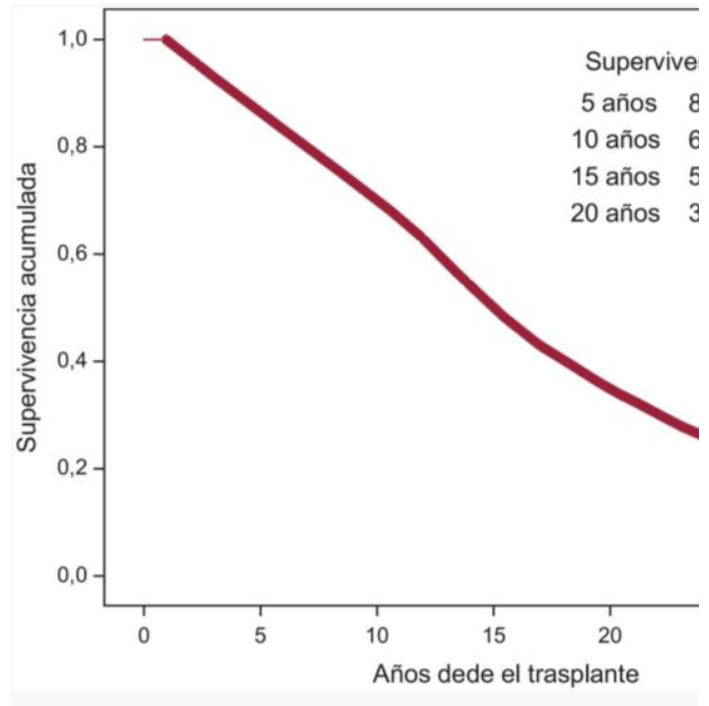

Figura 14. Curva de supervivencia condicionada a la supervivencia al primer año de toda la serie (1984-2015).

Los resultados en términos de supervivencia han ido mejorando constantemente a lo largo de la serie histórica (figura 15). Con respecto a la década 1984-1993, hay diferencias altamente significativas con las demás décadas y con el periodo 2014-2015. Respecto a la primera década, se produce una mejora de la supervivencia al primer año en las siguientes 2 décadas. Respecto a los procedimientos realizados entre 1993 y 2013, en los años 2014 y 2015 se detecta una mejora adicional de la supervivencia a 1 año (tabla 5). La mejora de la supervivencia en la década 2004 2013 respecto a 1994-2014 se observa a más largo plazo (a partir del segundo año tras el trasplante) (figura 15). El aumento de la mediana de supervivencia es constante: 9,1 años (19841993), 10,9 (1994-2003), 12,0 (2004-2013). Asimismo, el periodo 2014-2015 muestra una tendencia clara a la mejora de la supervivencia respecto a la década previa (2004-2013), si bien no alcanza significación estadística debido al relativamente pequeño tamaño muestral del grupo más contemporáneo.

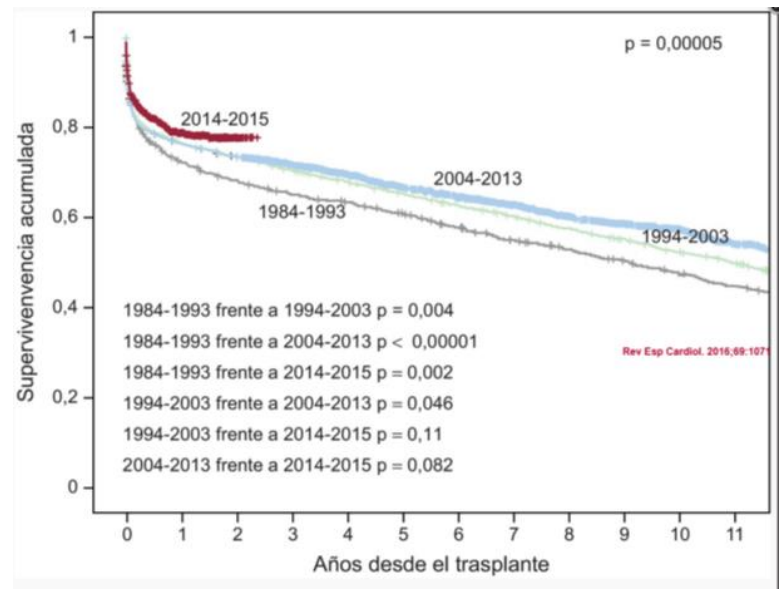

Figura 15. Curvas de supervivencia según el periodo de trasplante (intervalos de 10 años, 1984-2013 y 2014-2015). 
Tabla 5. Análisis univariable de supervivencia según las características basales del receptor, el donante y el procedimiento (1984-2015)

\begin{tabular}{|c|c|c|c|}
\hline & HR (IC95\%) & $\mathrm{p}$ & $\begin{array}{l}\text { Supervivencia (años), } \\
\text { mediana (IC95\%) }\end{array}$ \\
\hline \multicolumn{4}{|l|}{ Edad del receptor } \\
\hline$<16$ años & 1 & & $15,8(11,6-20,0)$ \\
\hline 16-60 años & $1,2(1,1-1,4)$ & 0,008 & $11,7(11,1-12,2)$ \\
\hline$>60$ años & $1,6(1,3-1,9)$ & $<0,001$ & $8,6(7,8-9,4)$ \\
\hline \multicolumn{4}{|l|}{ Tipo de trasplante } \\
\hline Trasplante aislado & 1 & & $11,3(10,0-11,7)$ \\
\hline Trasplante combinado & $1,3(1,1-1,6)$ & 0,01 & $7,4(3,9-10,8)$ \\
\hline Retrasplante & $1,7(1,4-2,1)$ & $<0,001$ & $3,8(1,1-6,6)$ \\
\hline \multicolumn{4}{|l|}{ Edad del donante } \\
\hline$\leq 45$ años & 1 & & $11,6(11,1-12,1)$ \\
\hline$>45$ años & $1,2(1,1-1,3)$ & $<0,001$ & $9,0(8,0-9,9)$ \\
\hline \multicolumn{4}{|l|}{ Código de urgencia } \\
\hline Electivo & 1 & & $11,5(11,0-12,0)$ \\
\hline Urgente & $1,1(1,1-1,2)$ & $<0,001$ & $9,8(8,6-10,9)$ \\
\hline \multicolumn{4}{|l|}{ Tipo de asistencia ${ }^{*}$} \\
\hline Sin asistencia & 1 & & - \\
\hline Balón de contrapulsación & $1,2(0,9-1,2)$ & 0,13 & - \\
\hline ECMO & $1,6(1,2-2,1)$ & 0,003 & - \\
\hline Asistencia ventricular & $0,9(0,7-1,3)$ & 0,77 & - \\
\hline
\end{tabular}

ECMO: oxigenador extracorpóreo de membrana; HR: hazard ratio; IC95\%: intervalo de confianza del $95 \%$.

* Pacientes trasplantados entre 2009 y 2015.

\section{Causas de fallecimiento}

En la población total, la causa de muerte más frecuente es la enfermedad vascular del injerto/muerte súbita $(18,7 \%)$, seguida de las infecciones $(17,1 \%)$, el fallo primario del injerto $(13,6 \%)$ y las neoplasias $(13,1 \%)$ (figura 16). Las causas de fallecimiento cambian según el tiempo tras el trasplante que se considere (figura 16). En el primer mes tras el trasplante, casi el $50 \%$ de los fallecimientos se producen por fallo primario del injerto. Después del primer mes y hasta cumplir el primer año, el rechazo agudo $(15,3 \%) \mathrm{y}$, sobre todo, las infecciones $(36,6 \%)$ son la principal causa de muerte. Después del primer año, la causa mayoritaria es las distintas manifestaciones de la enfermedad vascular del injerto $(30,2 \%)$ y los tumores $(22,0 \%)$. Con el paso del tiempo, las principales causas de muerte en el primer año han cambiado significativamente, con una disminución de las muertes debidas a rechazo agudo y un incremento de los fallecimientos por fallo primario del injerto, si bien estos han disminuido en el periodo 2014-2015 (figura 17). En las muertes ocurridas entre el primer año y el quinto después del trasplante, se observa una tendencia a la disminución de las muertes por enfermedad vascular del injerto/muerte súbita y un aumento significativo de las muertes por rechazo agudo (figura 18). 


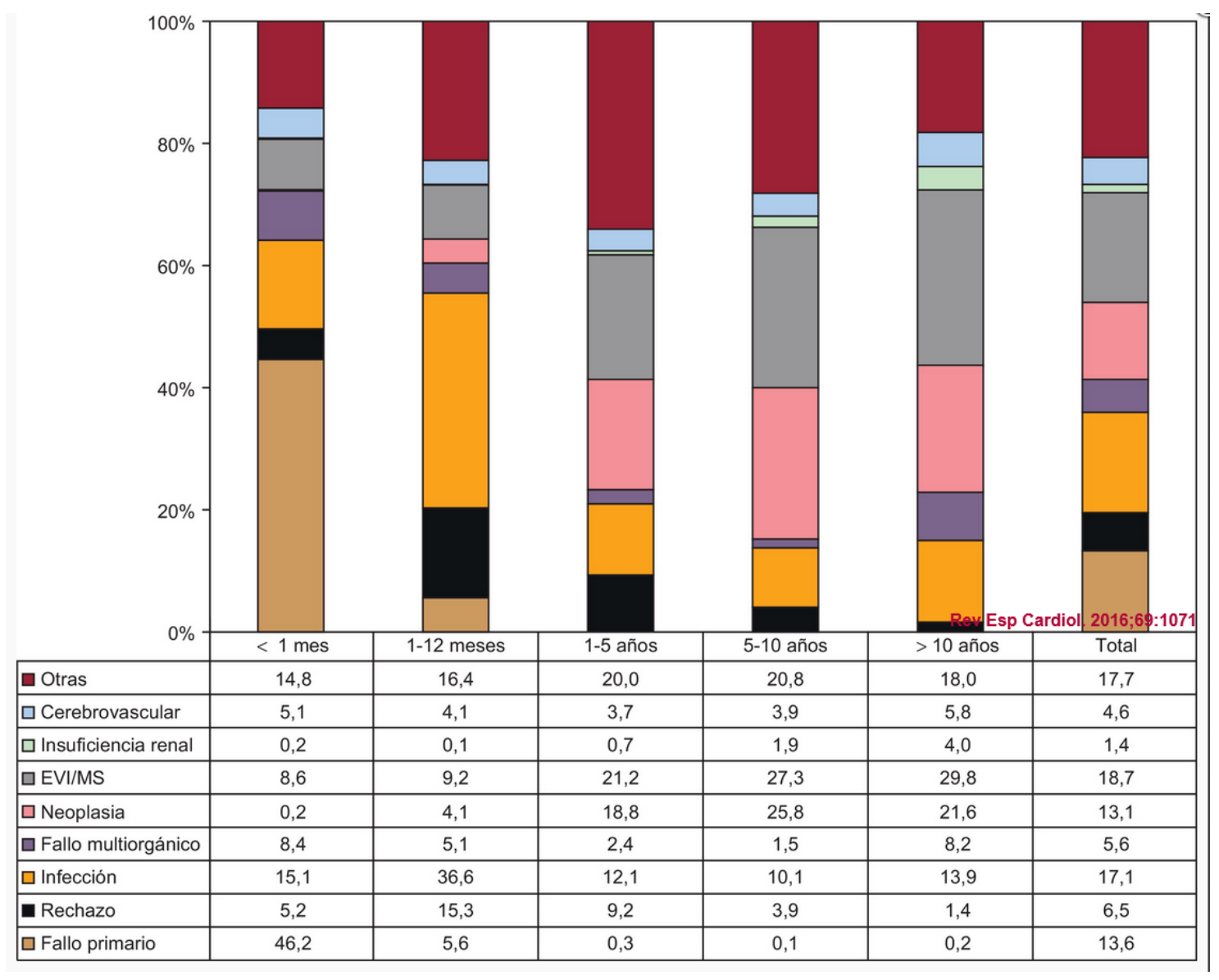

Figura 16. Causas de muerte según tiempo desde el trasplante y en toda la serie (1984-2015). EVI: enfermedad vascular del injerto; MS: muerte súbita. 


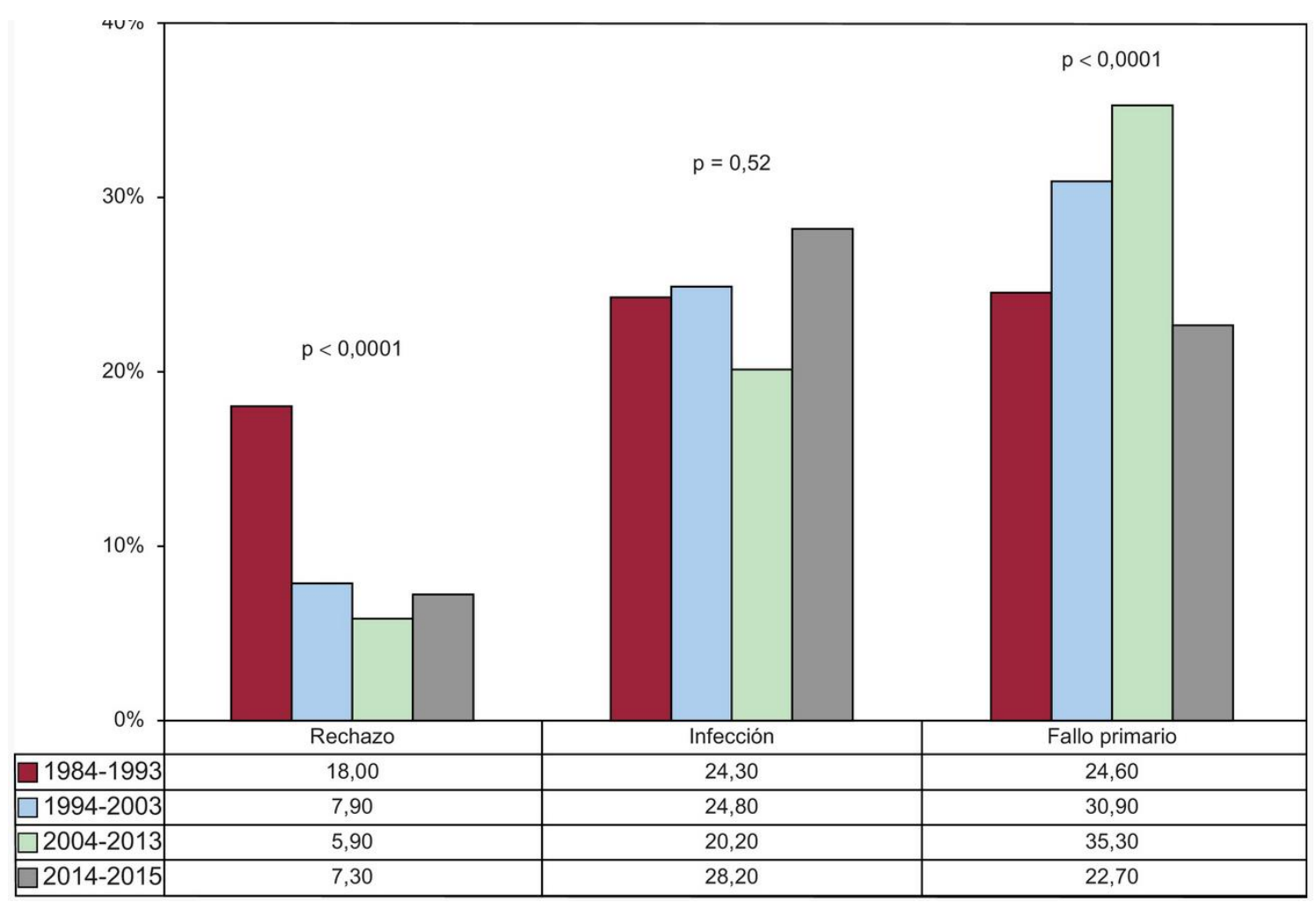

Figura 17. Causas de muerte principales en el primer año después del trasplante en toda la serie (1984-2015).

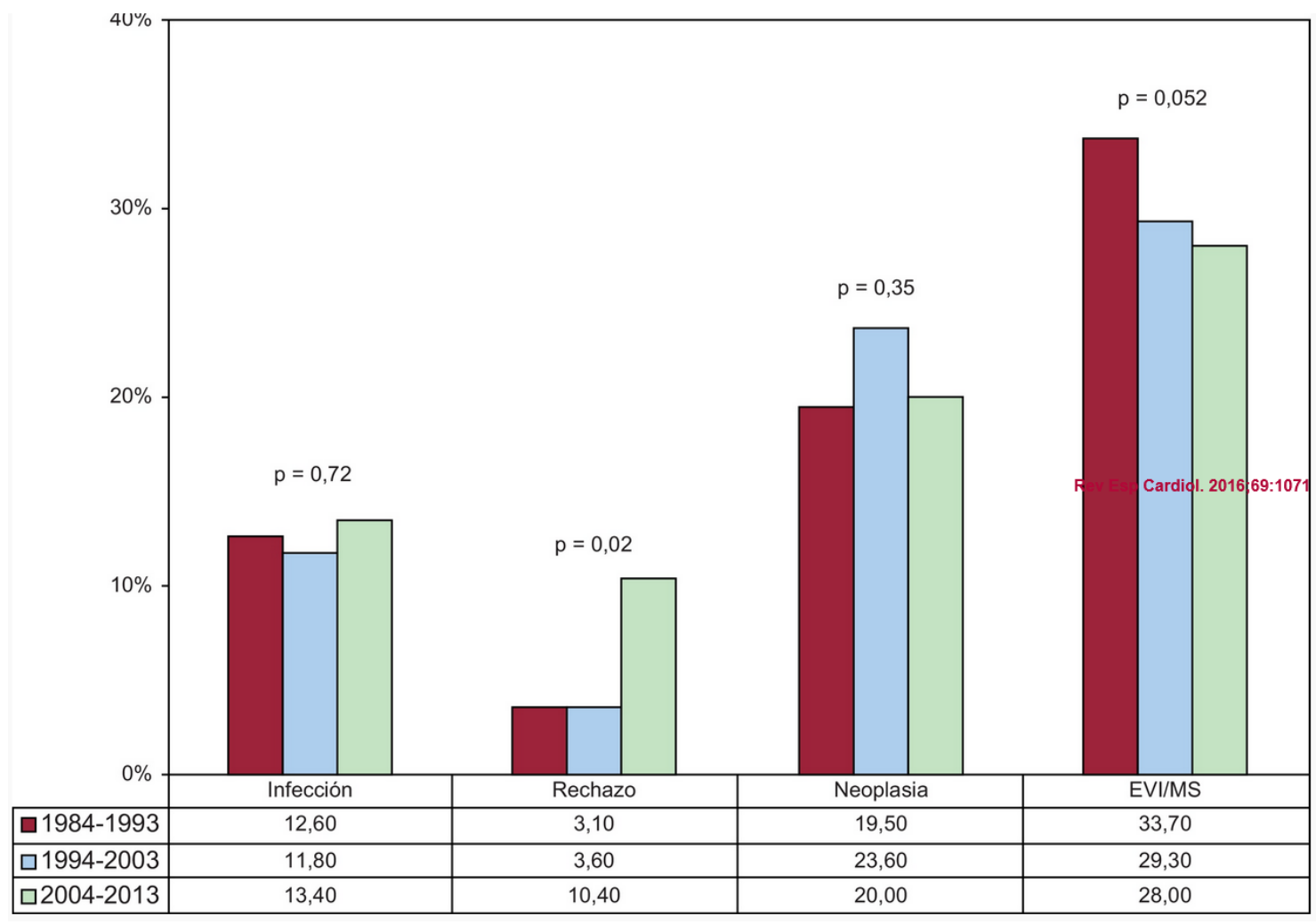

Figura 18. Causas de muerte principales ocurridas entre el primer y el quinto año tras el trasplante en toda la serie (19842015). EVI: enfermedad vascular del injerto; MS: muerte súbita. 


\section{DISCUSIÓN}

Con la perspectiva histórica que ofrece la actividad del RETC durante más de 30 años, con datos prácticamente de todos los pacientes con trasplante cardiaco en España, el hallazgo más relevante es la evolución de los resultados en supervivencia. Después de la mejora en la supervivencia precoz en la segunda década de actividad (1994-2003), mantenida en la siguiente (2004-2013), en los últimos 2 años se observa una mejora adicional, con supervivencia a 1 año cercana al $80 \%$. A medio-largo plazo, por su parte, la mejora se ha mantenido constante, y analizando la tendencia de la curva de los años 2014-2015 es de esperar que se mantenga en el futuro. Tanto las cifras como las tendencias son prácticamente superponibles a las publicadas en el registro de la International Society for Heart and Lung Transplantation para el periodo comprendido entre 1982 y $2013^{27}$. Dicho registro, no obstante, aunque incluye a más de 100.000 pacientes de todo el mundo, al contrario que el RETC, tiene un sesgo de selección, ya que no se recoge a todos los pacientes trasplantados debido a su carácter voluntario.

Hay que destacar que la mejora observada en la supervivencia se ha producido en un contexto de complejidad creciente de los receptores, los donantes y el procedimiento quirúrgico, que se mantiene desde el 2009 aproximadamente. En este sentido, resulta de interés el alto porcentaje de trasplantes realizados en código de urgencia (prácticamente la mitad de los procedimientos) junto con el creciente uso de dispositivos de asistencia circulatoria. El 2015, menos de un cuarto de los trasplantes urgentes se han realizado con balón de contrapulsación, un procedimiento de asistencia que era mayoritario hasta 2014. El uso de ECMO previo al trasplante se mantiene aproximadamente estable desde 2013 y se ha duplicado el uso de dispositivos de asistencia ventricular de flujo continuo. Aunque la necesidad de asistencia circulatoria antes del trasplante y el uso de ECMO para brindarla conllevan mayor mortalidad precoz, el descenso observado en la mortalidad precoz por fallo primario del injerto probablemente esté relacionado con el uso y el cuidado juicioso de los receptores a los que se trasplanta con dispositivos de asistencia ventricular de flujo continuo. Esto justificaría que la supervivencia a corto y medio plazo sea estadísticamente similar para el trasplante electivo y el realizado con el uso previo de estos últimos dispositivos.

Otra observación interesante es que la mejora de la supervivencia en periodos recientes no solo se debe a la mejora en la mortalidad precoz (en el primer año). Las curvas entre periodos se separan a partir del segundo año, una tendencia que parece acentuarse para los pacientes trasplantados en los últimos 2 años, si bien habrá que esperar una evolución más larga para confirmar este hallazgo. Aunque la causa de esta observación es sin duda multifactorial, es destacable la disminución de la enfermedad vascular del injerto como causa de mortalidad a medio plazo observada en los periodos más recientes.

\section{CONCLUSIONES}

La actividad del trasplante cardiaco en España se mantiene estable en los últimos años, con alrededor de 250 procedimientos/año. A pesar del empeoramiento y la complejidad del contexto clínico actual (uso de donantes no óptimos, asistencia circulatoria mecánica), los grupos españoles han conseguido mantener los resultados en mortalidad y se apunta a una progresiva mejora del pronóstico a medio plazo.

\section{FINANCIACIÓN}

El RETC está parcialmente financiado por una beca no condicionada de Novartis. 


\section{CONFLICTO DE INTERESES}

F. González-Vílchez recibe remuneración por participar en Comité de Control y Análisis Estadístico de Roche y Astellas, por ponencias, presentaciones educativas y gastos de viaje de Roche, Astellas y Novartis y soporte no condicionado del Instituto de Investigación Marqués de Valdecilla.

\section{AGRADECIMIENTOS}

Agradecemos el apoyo estadístico realizado por ODDS, S.L. Gran parte de los investigadores y centros participantes forman parte de la Red de Investigación Cardiovascular del Instituto de Salud Carlos III.

\section{ANEXO. Colaboradores del Registro Español de Trasplante Cardiaco 1984-2015}

Clínica Universitaria Puerta de Hierro, Majadahonda, Madrid

Hospital Universitario y Politécnico La Fe, Valencia

Hospital Universitario de A Coruña, A Coruña

Hospital Universitario Reina Sofía, Córdoba

Hospital Universitario Marqués de Manuel Cobo, Miguel Llano-Cardenal, José A. Vázquez de Prada, Valdecilla, Santander

Hospital Gregorio Marañón (adultos), Madrid

Hospital Universitario Doce de Octubre, Madrid

Hospital de la Santa Creu i Sant Pau, Barcelona

Hospital Universitario Virgen del Rocío, Sevilla

Hospital Universitario de Bellvitge, L'Hospitalet de Llobregat, Barcelona

Clínica Universitaria de Navarra, Pamplona

Hospital Clínic Universitari, Barcelona

Hospital Universitario Central de Asturias, Oviedo

Hospital Universitario Gregorio Marañón (infantil), Madrid

Hospital Universitario Virgen de la Arrixaca, Murcia
Manuel Gómez-Bueno, Francisco Hernández-Pérez, Luis Alonso-Pulpón, Alberto Forteza-Gil, Santiago Serrano-Fiz, Raúl Burgos-Lázaro, Carlos García-Montero, Evaristo Castedo-Mejuto

Ignacio Sánchez-Lázaro, Luis Martínez-Dolz, Mónica Cebrián-Pinar, Soledad Martínez-Penades

María J. Paniagua-Martin, Eduardo Barge-Caballero, Jose J. CuencaCastillo, Francisco Estevez-Cid, Gonzalo Barge-Caballero

Amador Lopez-Granados, Juan Carlos Castillo-Diéguez Francisco Nistal-Herrera

Paula Navas, Eduardo-Zataraín, Juan Fernández-Yáñez, Adolfo-Villa, Manuel Martínez-Sellés

Miguel Ángel Gómez-Sánchez, Laura Morán-Fernández

Viçens Brossa, Sònia Mirabet, Laura López

Ernesto Lage-Gallé, Diego Rangel-Sousa

Nicolás Manito, Josep Roca-Elías, Joel Salazar-Mendiguchía

Cristian Delgado-Domínguez, Ignacio Bibiloni-Lage

M. Ángeles Castel, Marta-Farrero, Ana García-Álvarez

José Luis Lambert, Beatriz Díez de Molina, María José BernardoRodríguez

Manuela Camino, Constancio Medrano

Domingo Pascual-Figal, Iris Garrido-Bravo, Francisco Pastor-Pérez 
Hospital Universitario Miguel Servet, Zaragoza

Hospital Clínico Universitario, Valladolid

Hospital Universitario La Paz, Madrid

Hospital Universitario Vall d'Hebron, Barcelona
Teresa Blasco-Peiró, Marisa Sanz-Julvé, Ana Pórtoles-Ocampo

Luis de la Fuente-Galán, Javier López-Díaz, Ana María Correa Fernández

Luis García-Guereta, Luz Polo, Carlos Labrandero

Dimpna C. Albert-Brotons, Ferrán Gran-Ipiña, Raúl Abella

\section{BIBLIOGRAFÍA}

1. Vázquez de Prada JA. Registro Español de Trasplante Cardiaco. Primer Informe Oficial. Rev Esp Cardiol. 1991:44:293-6.

2. Vázquez de Prada JA. Registro Español de Trasplante Cardiaco. Segundo Informe Oficial 1991. Rev Esp Cardiol. 1992;45:5-8.

3. Arizón JM, Segura J, Anguita M, Vázquez de Prada JA. Registro Español de Trasplante Cardiaco. Tercer Informe Oficial. Rev Esp Cardiol. 1992;45:618-21.

4. Arizón del Prado JM. Registro Español de Trasplante Cardiaco. Cuarto Informe Oficial (19841992). Rev Esp Cardiol. 1993;46:791-5.

5. Arizón del Prado JM. Registro Español de Trasplante Cardiaco. Quinto Informe Oficial (19841993). Rev Esp Cardiol. 1994;47:791-5.

6. Arizón del Prado JM. Registro Español de Trasplante Cardiaco. Sexto Informe Oficial (19841994). Rev Esp Cardiol. 1995;48:792-7.

7. Arizón del Prado JM. Registro Español de Trasplante Cardiaco. Séptimo Informe Oficial (19841995). Rev Esp Cardiol. 1996;49:781-7.

8. Arizón del Prado JM. Registro Español de Trasplante Cardiaco. VIII Informe Oficial (19841996). Rev Esp Cardiol. 1997;50:826-32.

9. Almenar Bonet L. Registro Español de Trasplante Cardiaco. IX Informe Oficial (1984-1997). Rev Esp Cardiol. 1999;52:152-8.

10. Almenar Bonet L. Registro Español de Trasplante Cardiaco. X Informe Oficial (1984-1998). Rev Esp Cardiol. 1999;52:1121-9.

11. Almenar Bonet L. Registro Español de Trasplante Cardiaco. XI Informe Oficial (1984-1999). Rev Esp Cardiol. 2000;53:1639-45.

12. Almenar Bonet L. Registro Español de Trasplante Cardiaco. XII Informe Oficial (1984-2000). Rev Esp Cardiol. 2001;54:1305-10.

13. Almenar Bonet L. Registro Español de Trasplante Cardiaco. XIII Informe Oficial (1984-2001) Rev Esp Cardiol. 2002;55:1286-92.

14. Almenar Bonet L. Registro Español de Trasplante Cardiaco. XIV Informe Oficial (1984-2002) Rev Esp Cardiol. 2003;56:1210-7.

15. Almenar Bonet L. Registro Español de Trasplante Cardiaco. XV Informe Oficial (1984-2003). Rev Esp Cardiol. 2004;57:1197-204.

16. Almenar Bonet L. Registro Español de Trasplante Cardiaco. XVI Informe Oficial (1984-2004). Rev Esp Cardiol. 2005;58:1310-7.

17. Almenar Bonet L. Registro Español de Trasplante Cardiaco. XVII Informe Oficial (1984-2005). Rev Esp Cardiol. 2006;59:1283-91.

18. Almenar Bonet L. Registro Español de Trasplante Cardiaco. XVIII Informe Oficial de la Sección de Insuficiencia Cardiaca, Trasplante Cardiaco y Otras Alternativas terapéuticas de la Sociedad Española de Cardiología (1984-2006). Rev Esp Cardiol. 2007;60:1177-87.

19. Almenar Bonet L. Registro Español de Trasplante Cardiaco. XIX Informe Oficial de la Sección de Insuficiencia Cardiaca, Trasplante Cardiaco y Otras Alternativas terapéuticas de la Sociedad Española de Cardiología (1984-2007). Rev Esp Cardiol. 2008;61:1178-90.

20. Almenar Bonet L. Registro Español de Trasplante Cardiaco. XX Informe Oficial de la Sección de Insuficiencia Cardiaca y Trasplante Cardiaco de la Sociedad Española de Cardiología (19842008). Rev Esp Cardiol. 2009;62:1286-96.

21. Almenar L, Segovia J, Crespo-Leiro MG, Palomo J, Arizón JM, González-Vílchez F, et al. XXI Informe Oficial de la Sección de Insuficiencia Cardiaca y Trasplante Cardiaco de la Sociedad Española de Cardiología (1984-2009). Rev Esp Cardiol. 2010;63:1317-28. 
22. Almenar L, Segovia J, Crespo-Leiro MG, Palomo J, Arizón JM, Cobo M, et al, en representación de los Equipos Españoles de Trasplante Cardiaco. Registro Español de Trasplante Cardiaco. XXII Informe Oficial de la Sección de Insuficiencia Cardiaca y Trasplante Cardiaco de la Sociedad Española de Cardiología (1984-2010). Rev Esp Cardiol. 2011;64:1138-46.

23. Almenar L, Segovia J, Crespo-Leiro MG, Palomo J, Arizón JM, González-Vílchez F, Registro Español de Trasplante Cardiaca. XXIII Informe Oficial de la Sección de Insuficiencia Cardiaca y Trasplante Cardiaco de la Sociedad Española de Cardiología (1984-2011). Rev Esp Cardiol. 2012;65:1030-8.

24. González-Vílchez F, Gómez-Bueno M, Almenar L, Crespo-Leiro MG, Arizón JM, MartínezSellés M, et al, Registro Español de Trasplante Cardiaco. XXIV Informe Oficial de la Sección de Insuficiencia Cardiaca y Trasplante Cardiaco de la Sociedad Española de Cardiología (19842012). Rev Esp Cardiol. 2013;66:973-82.

25. González-Vílchez F, Gómez-Bueno M, Almenar L, Crespo-Leiro MG, Arizón JM, Palomo J, et al, Spanish Heart Transplantation Teams. Spanish Heart Transplantation Registry. 25th official report of the Spanish Society of Cardiology Working Group on Heart Failure and Heart Transplantation (1984-2013). Rev Esp Cardiol. 2014;67:1039-51.

26. González-Vílchez F, Segovia Cubero J, Almenar L, Crespo-Leiro MG, Arizón JM, Villa A, et al, Spanish Heart Transplantation Teams. Spanish Heart Transplantation Registry. 26th Official Report of the Spanish Society of Cardiology Working Group on Heart Failure and Heart Transplantation (1984-2014). Rev Esp Cardiol. 2015;68:1008-21.

27. The International Society for Heart \&Lung Transplantation. Registries - Heart/Lung Registries. 2015 slides. Adult heart trasplantation statistics. Slide 43 [citado 10 Jul 2016]. Disponible en: https://www.ishlt.org/registries/slides.asp?slides=heartLungRegistry. 